\title{
Importance of Skewness in Investor Utility: Evidence from the Chinese Stock Markets
}

\author{
Patrick Kuok Kun \\ University of Macau, Macau SAR, China \\ Email:patrickc@umac.mo
}

How to cite this paper: Kun, P.K. (2017) Importance of Skewness in Investor Utility: Evidence from the Chinese Stock Markets. Journal of Mathematical Finance, 7, 881-895. https://doi.org/10.4236/jmf.2017.74047

Received: April 5, 2017

Accepted: October 31, 2017

Published: November 3, 2017

Copyright $\odot 2017$ by authors and Scientific Research Publishing Inc. This work is licensed under the Creative Commons Attribution International License (CC BY 4.0).

http://creativecommons.org/licenses/by/4.0/

\begin{abstract}
The goal of this study is to evaluate the importance of skewness in investor utility when predicting stock market return by financial ratio variable. We use the daily time series of four major stock market indices of Shanghai Stock Exchanges and Shenzhen Stock Exchanges. We find evidence of predictability of price-to-earnings ratio and price-to-book ratio on the market returns. Using the evidence of predictability, we find evidence that including skewness leads higher utility. The comparison among different ways to calculate the skewness indicate the calculation method mostly used in popular statistical software may lead to the highest utility.
\end{abstract}

\section{Keywords}

Skewness, Predictive Regression, Investor Utility, Market Returns

\section{Introduction}

As the two stock markets in Mainland China, the Shanghai Stock Exchange (SSE) and the Shenzhen Stock Exchange (SZSE) began their operations in December 1990. In these two decades, both stock markets have dramatically expanded. In the Shanghai Stock Exchange, by the end of 2016, there were 1182 companies listed with a market value of 28,500 billion yuan, and the annual cumulative trading volume is 50,200 billion yuan. In the Shenzhen Stock Exchange there were 1870 companies listed, with a market value of 22.31 trillion yuan and annual cumulative trading volume of 77.6 trillion yuan by the end of 2016. Both Shanghai Stock Exchange and Shenzhen Stock Exchange were closed markets and only Chinese investors are allowed to trade at the early stage of operation. A pilot QFII scheme was introduced in 2002 that allows the international institutional investors may participate in the Chinese stock markets through Qualified Foreign Institutional Investors (QFII) scheme. The revised QFII rules and re- 
laxed qualification requirements governed by the Administrative Measures on Domestic Securities Investment of Qualified Foreign Institutional Investors were implemented in 2006. As of July 2017, 284 foreign institutions have been granted with QFII licenses; and the total quota is USD 93.27 billion. In November 2014, Hong Kong individual investors are allowed to trade Class A Shares traded in Shanghai Stock Exchange through the "Shanghai-Hong Kong Stock Connect". A similar arrangement is being negotiated between Hong Kong Stock Exchange and Shenzhen Stock Exchange.

Stock return predictability is one of the popular parts of the asset pricing studies. Using financial ratios to predict returns has attracted much attention. Some studies have attempted to use different ratios to predict stock returns (Campbell and Shiller, 1988a [1]; Campbell and Shiller, 1988b [2]; Fama and French, 1988 [3]; Kothari and Shanken, 1997 [4]; Lamont, 1998 [5]; Lewellen, 2004 [6]; Campbell and Yogo, 2006 [7]; Chen, 2009 [8]; Westerlund and Narayan, 2012 [9]; Westerlund and Narayan, 2015b [10]). Most of them find strong evidence that the dividend yield, the price-to-earnings and the price-to-book have stock returns predictability.

Some follow-up studies, which find evidence of stock return predictability, attempt to understand the economic significance of such predictability. The most common way to evaluate the economic significance is by a mean-variance utility function, which only takes account of the first (mean) and second (variance) moments of stock returns. Utility function is based on the utility theory, which is the cornerstone for explaining economic choices under risk and for understanding pricing in the asset market.

Whether the higher moments of the rates of return distribution should be neglected or not has been argued in many empirical as well as theoretical articles. Most of them suggest that the higher moment should not be neglected unless the rates of return distribution are believed to be normal. However, there is sufficient evidence to reject the belief that the rates of return are normally distributed (Ibbotson, 1975 [11]; Prakash, de Boyrie, and Moncarz, 2000 [12]). Including higher moments seems reasonable.

Higher moment may be neglected if the utility function is assumed to quadratic. Some studies have found that this assumption of quadratic utility function is only appropriate for relatively low rates of return (Tobin, 1958 [13]; Pratt, 1964 [14]). It seems that including the third (skewness) moment is necessary when constructing the utility function. After the consideration of skewness, the utility function becomes three-dimensional and will be a function of required expected rates of return, variance, and skewness.

Arditti (1967) shows that investors preferred the positively skewed rates of return distribution, which is consistent with the opinion of downsizing absolute risk aversion [15]. One of the explanations of the preference of positive skewness is the decrease in the probability of large negative rates of return. The primary goal of this study is to examine the importance of including skewness in evaluating the economic significance of the prediction ability of the financial ratio 
to Chinese stock market returns. We extend the literature by focusing on evaluating different measures of skewness.

The remainder of the paper is organized as follows. A brief literature review of including skewness in decision making is provided in Section 2. In Section 3, we describe the data, discuss the predictive regression model and present the preliminary results. In Section 4, we present the research methodologies employed. Section 5 discusses the main results. The conclusion and suggestion for future research are summarized in the last section, Section 6.

\section{Previous Literature}

The importance of skewness in financial economics research is documented in literatures. Some studies have studied the usefulness of including skewness in the determination of utility function, construction of portfolio evaluation model, and formulation of goal programming since Arditti (1967) find that the investors prefer the positively skewed rates of return distribution [15]. Following this study, Kraus and Litzenberger (1976) also find the investors' preference for positive skewness and suggest that the Sharpe-Lintner CAPM model should be extended to include systematic skewness [16]. On the basis of the last study, Prakash and Bear (1986) develops a method of incorporating skewness into a composite performance measure which has the desirable property than Treynor's reward-to-volatility measure which is in the absence of skewness [17]. Stephens and Proffitt (1991) extend the work to develop a generalized performance evaluation model which allows for multiple moments of utility and find that higher moments especially skewness has significant impact on the performance rankings of internationally diversified mutual funds [18]. Lai (1991) [19], Chunhachinda, Dandapanib, Hamidb, Prakash (1997) [20] and Prakash, Chang, Pactwa (2003) [21] explore the portfolio selection with skewness by formulating a goal programming that provides a set of weights for an optimum investment portfolio which satisfy some competing objectives that maximizes both the expected returns and positive skewness, and simultaneously minimize the risk (variance). These studies find evidences that when incorporating skewness into an investor's portfolio decision may cause a major change in the construction of the optimal portfolio. Bhattacharya (2003) find that in a Taylor's series expansion of expected utility function of wealth the coefficients of the second moment term is always zero, which implies the portfolio decision s are taken in the mean-skewness space rather than the mean-variance space [22]. This utility function developed by this study which includes skewness in the functional form indicates the investors are risk averse for wealth levels below their current wealth and they are risk seeker for wealth levels above their current wealth.

Some studies may find evidences that under departure from normality, including skewness (third-moment) or even kurtosis (fourth-moment) may improve the portfolio allocation optimization and increase the economic utility of the optimized portfolio. Patton (2004) find evidence of economic significance 
that the model capturing skewness yielded better portfolio decisions than the bivariate normal model, especially when the skewness-included model is being for the unconstrained portfolios [23]. Jondeau and Rockinger (2006) attempt a Taylor series expansion to approximate the expected utility of higher moments [24]; they find this approach can be easily applied under the situation of large number of assets and the third- or fourth-moment strategies may provide a good approximation of the expected utility. Mitton and Vorkink (2007) developed a utility function that accounts for skewness [25]; they find that portfolio returns of underdiversified investors are more positively skewed than those of diversified investors and the investors intentionally choose stocks may increase the skewness of their portfolio returns.

\section{Data and Preliminary Results}

\subsection{Data}

The data set consists of daily time series data of four major market indices in Shanghai and Shenzhen stock exchanges: 1) China Securities Index Company 100 Index (CSI 100); 2) CSI 300 Index (CSI 300); 3) Shanghai Stock Exchange Composite Index (SSE Composite); and 4) Shenzhen Stock Exchange Component Index (SZSE Component). For each of these four indices, three variables are extracted: market index, from which logarithmic returns are computed, price-to-book ratio $(\mathrm{PB})$ and price-to-earnings ratio $(\mathrm{PE})$. The sample period starts from 1 January 2007 to 31 December 2014, during which the data of these four variables are available, consisting of 1944 observations. All data are provided by the Wind Financial Terminal.

\subsection{Predictive Regression Model and Preliminary Results}

The predictive regression model are extensively used to test whether the past stock returns or prices, financial ratios, market indices, and other macroeconomic variables may be employed to forecast the stock returns or prices. The starting point in the following system of equations:

$$
\begin{aligned}
& S R_{t}=\alpha+\beta \cdot F R_{t-1}+\varepsilon_{t} \\
& F R_{t}=\phi+\rho \cdot F R_{t-1}+v_{t}
\end{aligned}
$$

where $S R_{t}$ is the stock market return in day $t, F R_{t}$ is the value of predictive variable which is the hypothesized financial ratios included in this study in day $t$, both $\varepsilon_{t}$ and $v_{t}$ are the error terms. In our case, $F R_{t}$ is either price-to-book ratio, or price-to-earnings ratio. The null hypothesis of no predictability, i.e. $\beta=0$ in Equation (1) may be tested against the alternative hypothesis $\beta>0$. Equation (2) indicates the predictive variable is assumed to follow a $\operatorname{AR}(1)$ process in which $\rho<1$. Following previous studies, we may assume the correlation between $\varepsilon_{t}$ and $v_{t}$ are negative.

This system of equations may be run simply by Ordinary Least Squares (OLS) estimation. However, Westerlund and Narayan (2012) raise the arguments that 
the OLS estimators may be inefficient and may have bias if the time series is endogenous, persistent, and heteroskedastic [9]:

- The existence of correlation between $\varepsilon_{t}$ and $v_{t}$ will make $\varepsilon_{t}$ correlated with $F R_{t}$ in the predictive regression. It violates one of the assumptions of OLS which requires independence at all lags; the possibility of endogeneity in $F R_{t}$ will make the OLS estimator of $\beta$ no longer unbiased.

- Finance literatures of financial ratio predictors always show evidence of persistency in the financial ratio variables. The effect of persistency of $F R_{t}$ will aggravate the OLS bias.

- OLS estimator is inefficient in the presence of heteroskedasticity. Financial data, especially high frequency data, is generally found to be heteroskedastic. Westerlund and Narayan (2015a) find evidence that when accounting for Autoregressive Conditional Heteroskedasticity (ARCH), there are significant efficiency gains in the estimators [26].

Table 1 presents the results of preliminary study on the market returns and

Table 1. Descriptive statistics of the time series variables.

\begin{tabular}{cccccc}
\hline & & $\begin{array}{c}\text { Stationarity: } \\
\text { ADF unit } \\
\text { root }\end{array}$ & $\begin{array}{c}\text { Persistence: } \\
\text { AR(1) } \\
\text { coefficient }\end{array}$ & $\begin{array}{c}\text { Endogeneity: } \\
\gamma\end{array}$ & $\begin{array}{c}\text { Heteroskedasticity: } \\
\text { ARCH LM test }\end{array}$ \\
\hline CSI 100 & Returns & $-18.9361^{* * *}$ & 0.0081 & & $32.8089^{* * *}$ \\
& PE & $-44.2272^{* * *}$ & $0.9985^{* * *}$ & $0.0307^{* * *}$ & $38.8577^{* * *}$ \\
CSI 300 & PB & $-24.9132^{* * *}$ & $0.9988^{* * *}$ & $0.2319^{* * *}$ & $27.2841^{* * *}$ \\
& Returns & $-21.4195^{* * *}$ & 0.0178 & & $39.0858^{* * *}$ \\
SSE & PE & $-43.9985^{* * *}$ & $0.9986^{* * *}$ & $0.0314^{* * *}$ & $58.1927^{* * *}$ \\
Composite & PB & $-24.7439^{* * *}$ & $0.9989^{* * *}$ & $0.2386^{* * *}$ & $43.4782^{* * *}$ \\
& Returns & $-21.7608^{* * *}$ & -0.0020 & & $47.7123^{* * *}$ \\
& PE & $-43.8773^{* * *}$ & $0.9986^{* * *}$ & $0.0274^{* * *}$ & $60.5641^{* * *}$ \\
SZSE & PB & $-44.4403^{* * *}$ & $0.9989^{* * *}$ & $0.2401^{* * *}$ & $49.7458^{* * *}$ \\
& Returns & $-21.1609^{* * *}$ & 0.0369 & & $33.8359^{* * *}$ \\
& & & & & $70.1312^{* * *}$ \\
& PE & $-23.2604^{* * *}$ & $0.9985^{* * *}$ & $0.0224^{* * *}$ & $88.3023^{* * *}$ \\
\hline
\end{tabular}

1) The table reports the results of preliminary study on the market returns and predictor variables. 2) The ADF (Augmented Dickey-Fuller) test statistic is reported in column 3, which tests the hypothesis that the time series is stationary. The ADF test tests the null hypothesis of non-stationarity, in which the $\delta$ coefficient in the regression $\Delta X_{t}=\beta_{0}+\delta X_{t-1}+\sum_{i=1}^{m} \alpha_{i} \Delta X_{t-i}+\varepsilon_{t}$ equals 0 . The optimal lag length is chosen by using the Schwarz Information Criterion (SIC). 3) The regression coefficient of AR(1) model of market returns and predictors is reported in column 4. The significance of the regression coefficient is tested. 4) The regression coefficient of the residuals from the predictive regression model [Equation (1)] of each predictor on the residuals from the $\mathrm{AR}(1)$ model of the predictor variable [Equation (2)], $\varepsilon_{t}=\eta+\gamma \cdot v_{t}$ is reported in column 5. The significance of the regression coefficient is tested. 5) The last column reports the $\mathrm{F}$ test statistics of the ARCH LM test on the residuals from the AR(12) model of market returns and predictor variables. The null hypothesis of no existence of ARCH effect is tested. 6$){ }^{*}$ Significance at $10 \%$; ${ }^{*}$ Significance at $5 \% ;{ }^{* *}$ Significance at $1 \%$. 
predictor variables. The Augmented Dickey-Fuller (ADF) test statistics indicate all the time series of stock market returns and the financial ratio predictors are stationary, which is a common assumption in many time series techniques. Some previous studies document that most of the financial ratio based predictors of market or stock returns are persistent. The $\mathrm{AR}(1)$ coefficients of the first-order autoregressive models of all financial ratio predictors are greater than 0.90 , which suggests the predictor variables are significantly persistent. The endogeneity of the financial ratio variables may be tested by regressing the residuals from the predictive regression model [ $\varepsilon_{t}$ in Equation (1)], on the residuals from the $\operatorname{AR}(1)$ model of the financial ratio $\left[v_{t}\right.$ in Equation (2)]. The slope coefficient of such regression is significantly different from zero, which implies the financial ratio predictors are endogenous. The heteroskedasticity of the residuals from filtering all time series by fitting an AR(12) model may be diagnosed by ARCH Lagrange Multiplier (LM) test. All the results suggest the null hypothesis of no ARCH effects should be rejected and suggest that the time series having heteroskedastic characteristic.

Table 2 presents the skewness of the market return and two financial variables measured by the conventional sample skewness formula, and the ordinary correlation between the market return and each financial variable. The null hypothesis of zero correlation is tested and the $t$ test statistics is reported in parenthesis. Similar to previous studies, the market returns are found to have negative skewness; on the other hand, financial ratios have positive skewness. The correlation analysis suggest there is a moderate relationship between market return and $\mathrm{PE}$ ratio, but does not suggest a relationship between market return and $\mathrm{PB}$

Table 2. Skewness and ordinary correlations of the time series variables.

\begin{tabular}{cccc}
\hline & & Skewness & Ordinary Correlation \\
\hline CSI 100 & Returns & -0.2529 & \\
& PE & 1.1437 & $0.0402(1.7743)^{*}$ \\
CSI 300 & PB & 1.3910 & $0.0211(0.9323)$ \\
& Returns & -0.3700 & \\
SSE Composite & PE & 1.4205 & $0.0475(2.0957)^{* *}$ \\
& Returns & -0.3849 & $0.0257(1.1369)$ \\
& PE & 1.1875 & $0.0391(1.7278)^{*}$ \\
SZSE Component & PB & 1.3633 & $0.0158(0.7003)$ \\
& Returns & -0.3502 & $0.0394(1.7416)^{*}$ \\
& PE & 1.2743 & $0.0436(1.9245)^{*}$ \\
& PB & 1.6071 &
\end{tabular}

1) The table reports statistics of skewness of the stock returns and two financial ratio variables-PB and $\mathrm{PE}$. 2) The last column reports ordinary correlation coefficients between market returns and $\mathrm{PB}$, and between market returns and PE. The t-statistics for testing the null hypothesis that correlation is zero are reported in parenthesis. 3) ${ }^{\star}$ Significance at $10 \% ;{ }^{* \star}$ Significance at $5 \%$; ${ }^{* *}$ Significance at $1 \%$. 
ratio except SZSE Component Index return.

\subsection{Biased-Adjusted Predictive Regression Model}

Because of the possibility of having biased and inefficient OLS estimators, Lewellen (2004) propose a bias-adjusted estimator to handle the unbiasedness issue [6]. The idea behind is to make Equation (1) conditional on the residuals of Equation (2), $v_{t}$. By substituting $\varepsilon_{t}=\gamma \cdot v_{t}+\eta_{t}$, the following augmented predictive regression may be obtained:

$$
S R_{t}=\alpha-\gamma \phi(1-\rho)+\beta \cdot F R_{t-1}+\gamma\left(F R_{t}-\rho \cdot F R_{t-1}\right)+\eta_{t}
$$

Even though $\rho$ is unknown, Lewellen (2004) proposes that we can put a lower bound on it by assuming that $\rho \approx 1$ [6]. Simulation results show that $\rho=0.9999$ is an appropriate value. Westerlund and Narayan (2015a) assume $\rho=1+\frac{c}{T}$, where $c$ stands for a drift parameter that measures the degree of persistency and requires that $c \leq 0$ [26]. It may be seen that if we set $c=0, F R_{t}$ is exactly a unit root process; if $c<0, F R_{t}$ is locally stationary and $\rho$ will approach 1 as $T$ increases. Since Lewellen (2004) bias-adjusted OLS is simply an OLS with $\rho=0.9999$, the ARCH structure inherent in the errors may be ignored [6]. However, since the data are weighted by $\frac{1}{\sigma_{\eta t}}$ in Westerlund and Narayan (2015a) flexible generalized least squares (FGLS), the ARCH structure may be exploited by FGLS [26].

To test whether the selected financial ratio variables price-to-earnings ratio $(\mathrm{PE})$ and price-to-book ratio $(\mathrm{PB})$ may be used to predict the market returns, the null hypothesis of no predictability $(\beta=0)$ in Equations (1) and (3) may be tested. The preliminary study shows that the market returns and predictor variables are all persistence, endogenous, and having heteroskedastic characteristics. It seems the conventional OLS estimators in the predictive regression model may be biased and inefficient. Both Lewellen (2004) [6] bias-adjusted least squares estimator (AOLS) and Westerlund-Narayan (2015a) [26] flexible generalized least squares estimator (FGLS) are possible candidates for inference and forecasting. AOLS estimator is unbiased but it is still inefficient. FGLS may provide not only unbiased but also efficient estimator, and FGLS may provide flexibilities to the time series which exhibit persistence, endogenous and heteroskedastic characteristics.

Table 3 presents the results of the predictive regression model using either PE or $\mathrm{PB}$ as the predictor. The row labeled OLS shows the conventional ordinary least squares estimator of regression coefficient $(\beta)$ and t-statistics. These estimates are biased and inefficient since the time series exhibit persistency, endogeneity and not homoskedasticity, are reported primarily as a benchmark. OLS results indicate that the predictor PE is slightly significantly predictive to the market returns; while PB does not have any predictive ability on the market returns. The predictive regression model using unbiased but inefficient AOLS 
Table 3. Predictive regression results.

\begin{tabular}{cccccc}
\hline \multicolumn{5}{c}{ Predictor } \\
\hline Panel A: & Estimator & PE & Theil U & PB & Theil U \\
\hline \multirow{2}{*}{ CSI 100 } & OLS & $7.08 \times 10^{-5}(1.7743)^{*}$ & 0.9591 & $2.79 \times 10^{-4}(0.9323)$ & 0.9763 \\
& AOLS & $5.05 \times 10^{-5}(1.9943)^{* *}$ & 0.3573 & $1.49 \times 10^{-5}(0.0859)$ & 0.3195 \\
& FGLS & $5.14 \times 10^{-5}(76.363)^{* * *}$ & 0.3563 & $1.58 \times 10^{-3}(23.657)^{* * *}$ & 0.3109 \\
CSI 300 & OLS & $8.28 \times 10^{-5}(2.0957)^{* *}$ & 0.9514 & $3.44 \times 10^{-4}(1.1369)$ & 0.9707 \\
& AOLS & $5.88 \times 10^{-5}(2.4871)^{* *}$ & 0.3313 & $6.10 \times 10^{-5}(0.3649)$ & 0.3007 \\
& FGLS & $3.14 \times 10^{-5}(12.037)^{* * *}$ & 0.3452 & $1.24 \times 10^{-3}(20.034)^{* * *}$ & 0.3515 \\
SSE & OLS & $5.60 \times 10^{-5}(1.7278)^{*}$ & 0.9611 & $2.03 \times 10^{-4}(0.7003)$ & 0.9833 \\
Composite & AOLS & $3.84 \times 10^{-5}(2.1169)^{* *}$ & 0.3058 & $9.16 \times 10^{-5}(0.6680)$ & 0.2512 \\
& FGLS & $1.93 \times 10^{-4}(20.024)^{* * *}$ & 0.3056 & $1.06 \times 10^{-3}(10.146)^{* * *}$ & 0.2531 \\
SZSE & OLS & $6.21 \times 10^{-5}(1.7416)^{*}$ & 0.9592 & $5.68 \times 10^{-4}(1.9245)^{*}$ & 0.9554 \\
Component & AOLS & $2.58 \times 10^{-5}(1.1442)$ & 0.3556 & $2.14 \times 10^{-4}(1.5351)$ & 0.2513 \\
& FGLS & $6.45 \times 10^{-5}(3.2057)^{* * *}$ & 0.3428 & $3.14 \times 10^{-4}(25.237)^{* * *}$ & 0.3018 \\
\hline
\end{tabular}

1) The table presents the results of the regression coefficient $\beta$ of the predictive regression model using different predictor, price-to-earnings ratio (PE) or price-to-book ratio (PB); and applying different estimator, ordinary least squares estimator (OLS), adjusted ordinary least squares estimator (AOLS) proposed in Lewellen (2004), or flexible generalized least squares estimator (FGLS) suggested in Westerlund and Narayan (2015a). 2) t-statistics of the null hypothesis of no predictability, i.e. $\beta=0$ are in the parentheses. 3) ${ }^{*}$ Significance at $10 \%$; ${ }^{*}$ Significance at $5 \%$; ${ }^{* *}$ Significance at $1 \%$.

estimators are also reported as a comparison. Same as the predictive model using OLS, the predictor PE is also found having predictive ability while PB hasn't. A lower Theil's $U$ statistics in the AOLS model indicates AOLS model performs better in forecasting than the OLS predictive model.

Since all the time series used in this study are persistent, endogenous, and have heteroskedastic characteristics, flexible generalized least squares estimator (FGLS) seems may produce unbiased and efficient estimation of the predictive model. The results of FGLS predictive model are presented in the row "FGLS". A lower Theil's $U$ indicates a better predicting ability than the OLS predictive model. The regression coefficient results indicate both predictors PE and PB are significant predictors of all market index returns when using FGLS estimator. Our finding finds that PE may predict market returns more successfully than PB. PB becomes significant only when we apply FGLS estimators but PE is significant across the models applying different estimators. However, the consensus in the literatures is that PB predicts market return more successfully. This discrepancy may imply the Chinese stock market investors are more sensitive on the changes in the average price-to-earnings ratio of the stock market.

\section{Research Methodologies}

\subsection{Utility Function}

After we have used the predictive regression model to make forecast of the stock market returns, the investor's utility of the forecasts may be estimated by utility 
function. The utility function without considering the higher-than-second moment may be referred to as "Traditional Investor" Utility Function, which is a standard quadratic utility function and takes the following form:

$$
U_{2}=E\left(S R_{t+1}\right)-\frac{1}{2 \tau} \operatorname{Var}\left(S R_{t+1}\right)
$$

where $E\left(S R_{t+1}\right)$ and $\operatorname{Var}\left(S R_{t+1}\right)$ is the expected and the variance of the return of the forecast of stock market returns respectively, $\tau$ is the coefficient of risk aversion which requires that $\tau>0$. Finance literatures have documented this form of utility function is a reasonable approximation of standard expected utility function [e.g. Levy and Markowitz (1979) [27]; Hlawitschka (1994) [28]].

Following Scott and Horvath (1980) [29] and Mitton and Vorkink (2007) [25], the utility function accounting for the third-moment (skewness) is referred to as "Lotto Investor" Utility Function which takes the following forms:

$$
U_{3}=E\left(S R_{t-1}\right)-\frac{1}{2 \tau} \operatorname{Var}\left(S R_{t-1}\right)+\frac{1}{3 \phi} \operatorname{Skew}\left(S R_{t-1}\right)
$$

where $E\left(S R_{t+1}\right)$ and $\operatorname{Var}\left(S R_{t+1}\right)$ is the expected and the variance of the return of the forecast of stock market returns respectively, $\phi$ is the skewness preference coefficient which requires that $\phi>0$. Positive $\phi$ indicates a preference for positive skewness and the investor utility based on skewness should lead to higher investor utility. However, some studies criticize this "Lotto Investor" form isolating the impact of heterogeneity in skewness preference while maintains the homogeneity across preference for mean and variance. Mitton and Vorkink (2007) set the values of both risk-aversion and skewness preference parameters $(\tau, \phi)$ to be 2.5 and they justify that their choice is consistent with general perceptions governing the risk-aversion coefficient ranges [25].

\subsection{Measure of Skewness}

Since Pearson (1895) proposed a statistic to measure the skewness, statisticians have studied extensively the properties, utilities and limitations of various statistics of skewness for a century [30]. Statisticians discuss skewness in terms of the second $\left(m_{2}\right)$ and third $\left(m_{3}\right)$ moments around the mean, which are computed by $m_{2}=\frac{1}{n} \sum_{i=1}^{n}\left(X_{i}-\bar{X}\right)^{2}$ and $m_{3}=\frac{1}{n} \sum_{i=1}^{n}\left(X_{i}-\bar{X}\right)^{3} \quad$ respectively, where $\bar{X}$ is the sample mean of $X$.

The first version of skewness calculation is only used by a few statistical software packages (e.g. Visual Statistics, early versions of Stata and Minitab) but may be found in some mathematical statistics textbooks. It is named Fisher-Pearson coefficient of skewness and takes the following form:

$$
S K_{1}=\frac{m_{3}}{\left(m_{2}\right)^{3 / 2}}=\frac{\frac{1}{n} \sum_{i=1}^{n}\left(X_{i}-\bar{X}\right)^{3}}{\left[\frac{1}{n} \sum_{i=1}^{n}\left(X_{i}-\bar{X}\right)^{2}\right]^{3 / 2}}
$$


However, most current statistical software packages (e.g. Minitab, Microsoft Excel, SPSS, SAS) include an adjustment for sample size in the calculation of skewness coefficient. It is the adjusted Fisher-Pearson standardized moment coefficient and takes this form:

$$
S K_{2}=\frac{n}{(n-1)(n-2)} \sum_{i=1}^{n}\left(\frac{X_{i}-\bar{X}}{S_{X}}\right)^{3}
$$

where $S_{X}$ is the sample standard deviation of $X . S K_{2}$ may take an alternative form which includes an adjustment for sample size approaches unity as $n$ increases:

$$
S K_{2}=\frac{\sqrt{n(n-1)}}{n-2}\left[\frac{\frac{1}{n} \sum_{i=1}^{n}\left(X_{i}-\bar{X}\right)^{3}}{\left(\frac{1}{n} \sum_{i=1}^{n}\left(X_{i}-\bar{X}\right)^{2}\right)^{3 / 2}}\right]
$$

Jones and Gill (1998) compare the bias and mean squared error (MSE) of different measure of skewness and find that $S K_{2}$ performs better than $S K_{1} . S K_{2}$ has smaller MSE in samples if they are chosen from a skewed population [31].

Finally, few people are aware of the formula of computing skewness coefficient which is used in one econometric package, EViews, since it is buried within the help files. It includes an estimator for the standard deviation that is based on the biased estimator for the variance $\hat{\sigma}_{X}=S_{X} \sqrt{\left(\frac{n-1}{n}\right)}$ :

$$
S K_{3}=\frac{1}{n}\left[\sum_{i=1}^{n}\left(\frac{X_{i}-\bar{X}}{\hat{\sigma}_{X}}\right)^{3}\right]=\frac{1}{n}\left[\sum_{i=1}^{n}\left(\frac{X_{i}-\bar{X}}{S_{X} \sqrt{\left(\frac{n-1}{n}\right)}}\right)^{3}\right]
$$

All the skewness mentioned above are the measures used in statistical software. However, there is one forgotten measure of skewness in older mathematical statistics textbook (Yule and Kendall, 1950 [32]; Clark and Schkade, 1974 [33]). This measure directly compares the mean and median as follow:

$$
S K_{4}=3 \frac{(\bar{X}-\text { median })}{S_{X}}
$$

This statistic is consistent with the way we like to talk about skewness, easy to compute and interpret, and only requires three statistics (mean, median, and standard deviation).

\section{Main Results}

The results of the difference between the investors' utility obtained from different utility functions are presented in Table 4 and Table 5. Table 4 mainly presents the comparison results between the utility obtained by including skewness (Equation (5)) and that excluding skewness (Equation (4)). The results are 
Table 4. Utility differences between the utility functions with and without including skewness.

\begin{tabular}{|c|c|c|c|c|c|c|}
\hline Panel A: & Estimator & Predictor & $U_{3(S K 1)}-U_{2}$ & $U_{3(\text { (SK2) }}-U_{2}$ & $U_{3(\text { SK } 3)}-U_{2}$ & $U_{3(S K 4)}-U_{2}$ \\
\hline \multirow[t]{6}{*}{ CSI 100} & OLS & $\mathrm{PE}$ & 0.1524979 & 0.1526156 & 0.1524993 & 0.1351201 \\
\hline & & $\mathrm{PB}$ & 0.1854765 & 0.1856197 & 0.1854673 & 0.0977987 \\
\hline & AOLS & $\mathrm{PE}$ & 0.0131833 & 0.0131935 & 0.0131832 & 0.0037411 \\
\hline & & $\mathrm{PB}$ & 0.0264872 & 0.0265077 & 0.0264868 & 0.0047424 \\
\hline & FGLS & $\mathrm{PE}$ & 0.0120899 & 0.0120992 & 0.0120903 & 0.0035177 \\
\hline & & $\mathrm{PB}$ & 0.0469317 & 0.0469680 & 0.0469304 & 0.0362444 \\
\hline \multirow[t]{6}{*}{ CSI 300} & OLS & $\mathrm{PE}$ & 0.1522523 & 0.1523699 & 0.1522517 & 0.1462222 \\
\hline & & $\mathrm{PB}$ & 0.1894076 & 0.1895539 & 0.1894059 & 0.1000078 \\
\hline & AOLS & $\mathrm{PE}$ & 0.0395748 & 0.0396054 & 0.0395749 & 0.0020492 \\
\hline & & $\mathrm{PB}$ & 0.0253435 & 0.0253631 & 0.0253440 & 0.0026795 \\
\hline & FGLS & $\mathrm{PE}$ & 0.0507375 & 0.0507767 & 0.0507387 & 0.0019753 \\
\hline & & $\mathrm{PB}$ & 0.1075630 & 0.1076461 & 0.1075636 & 0.0406054 \\
\hline SSE & OLS & $\mathrm{PE}$ & 0.1583343 & 0.1584565 & 0.1583352 & 0.1563952 \\
\hline \multirow[t]{5}{*}{ Composite } & & PB & 0.1817683 & 0.1819087 & 0.1817740 & 0.0920101 \\
\hline & AOLS & $\mathrm{PE}$ & 0.0651985 & 0.0652489 & 0.0651972 & 0.0036314 \\
\hline & & $\mathrm{PB}$ & 0.0495767 & 0.0496150 & 0.0495767 & 0.0063621 \\
\hline & FGLS & $\mathrm{PE}$ & 0.1613704 & 0.1614951 & 0.1613705 & 0.0417918 \\
\hline & & $\mathrm{PB}$ & 0.0921656 & 0.0922368 & 0.0921659 & 0.0304367 \\
\hline SZSE & OLS & $\mathrm{PE}$ & 0.1699075 & 0.1700387 & 0.1699075 & 0.1657784 \\
\hline \multirow[t]{5}{*}{ Component } & & $\mathrm{PB}$ & 0.2142779 & 0.2144433 & 0.2142803 & 0.1000440 \\
\hline & AOLS & $\mathrm{PE}$ & 0.0878066 & 0.0878745 & 0.0878077 & 0.0006153 \\
\hline & & PB & 0.0870442 & 0.0871115 & 0.0870440 & 0.0037958 \\
\hline & FGLS & $\mathrm{PE}$ & 0.0216614 & 0.0216781 & 0.0216600 & 0.0261532 \\
\hline & & PB & 0.2524195 & 0.2526146 & 0.2524097 & 0.0647129 \\
\hline
\end{tabular}

1) This table presents the difference between the investors' utility obtained from the utility function including the skewness (Equation (5)) and that from the utility function excluding the skewness (Equation (4)). 2) Column 2 indicates the estimator being used in the predictive regression model, conventional ordinary least squares estimator (OLS), adjusted ordinary least squares estimator (AOLS) proposed in Lewellen (2004), and flexible generalized least squares estimator (FGLS) suggested in Westerlund and Narayan (2015a). 3) Column 3 indicates the predictor being used in the predictive regression model. 4) Columns 4 to 7 indicate the difference between the investors' utility obtained from the utility function including skewness and that excluding skewness. $S K_{1}$ is the Fisher-Pearson coefficient of skewness (Equation (6)), $S K_{2}$ is the adjusted Fisher-Pearson standardized moment coefficient (Equation (8)), $S K_{3}$ is the skewness coefficient used in EViews (Equation (9)), and $S K_{4}$ is the skewness coefficient previously used in some older mathematical textbooks (Equation (10)). 5) Positive difference implies that if we let skewness come into play in preference, it will be preferred to these utility functions without a skewness measure.

quite united that including skewness in the utility function may provide a positive gain in utility across different time series and different estimator, which suggest that skewness is an important factor in maximizing investor utility and must be considered when evaluating the investor's utility.

We may also notice that the predictor price-to-book ratio $(\mathrm{PB})$ may generally 
Table 5. Utility differences between the utility functions using different measures of skewness.

\begin{tabular}{|c|c|c|c|c|c|c|c|c|}
\hline Panel B: & Estimator & Predictor & $U_{3(S K 1)}-U_{3(S K 2)}$ & $U_{3(\text { (SK1) }}-U_{3(\text { (КК } 3)}$ & $U_{3(S K 1)}-U_{3(S K 4)}$ & $U_{3(S K 2)}-U_{3(S K 3)}$ & $U_{3(S K 2)}-U_{3(S K 4)}$ & $U_{3(S K 3)}-U_{3(S K 4)}$ \\
\hline \multirow[t]{6}{*}{ CSI 100} & OLS & $\mathrm{PE}$ & -0.0001177 & -0.0000015 & 0.0173778 & 0.0001163 & 0.0174955 & 0.0173792 \\
\hline & & $\mathrm{PB}$ & -0.0001432 & 0.0000092 & 0.0876778 & 0.0001524 & 0.0878210 & 0.0876686 \\
\hline & AOLS & PE & -0.0000102 & 0.0000001 & 0.0094423 & 0.0000103 & 0.0094524 & 0.0094421 \\
\hline & & $\mathrm{PB}$ & -0.0000205 & 0.0000004 & 0.0217448 & 0.0000209 & 0.0217653 & 0.0217444 \\
\hline & FGLS & $\mathrm{PE}$ & -0.0000093 & -0.0000004 & 0.0085722 & 0.0000090 & 0.0085815 & 0.0085726 \\
\hline & & $\mathrm{PB}$ & -0.0000363 & 0.0000013 & 0.0106874 & 0.0000376 & 0.0107236 & 0.0106860 \\
\hline \multirow[t]{6}{*}{ CSI 300} & OLS & $\mathrm{PE}$ & -0.0001176 & 0.0000005 & 0.0060300 & 0.0001181 & 0.0061477 & 0.0060295 \\
\hline & & PB & -0.0001463 & 0.0000017 & 0.0893998 & 0.0001481 & 0.0895461 & 0.0893980 \\
\hline & AOLS & $\mathrm{PE}$ & -0.0000306 & -0.0000001 & -0.0416240 & 0.0000305 & -0.0416545 & -0.0416241 \\
\hline & & $\mathrm{PB}$ & -0.0000196 & -0.0000005 & 0.0226640 & 0.0000191 & 0.0226836 & 0.0226645 \\
\hline & FGLS & $\mathrm{PE}$ & -0.0000392 & -0.0000012 & 0.0487622 & 0.0000380 & 0.0488014 & 0.0487634 \\
\hline & & PB & -0.0000831 & -0.0000006 & 0.0669576 & 0.0000825 & 0.0670407 & 0.0669582 \\
\hline SSE & OLS & $\mathrm{PE}$ & -0.0001223 & -0.0000009 & 0.0019391 & 0.0001213 & 0.0020614 & 0.0019400 \\
\hline \multirow[t]{5}{*}{ Composite } & & $\mathrm{PB}$ & -0.0001404 & -0.0000057 & 0.0897582 & 0.0001347 & 0.0898986 & 0.0897639 \\
\hline & AOLS & $\mathrm{PE}$ & -0.0000504 & 0.0000013 & 0.0615671 & 0.0000517 & 0.0616175 & 0.0615658 \\
\hline & & PB & -0.0000383 & 0.0000001 & 0.0432146 & 0.0000384 & 0.0432530 & 0.0432146 \\
\hline & FGLS & PE & -0.0001247 & -0.0000001 & 0.1195786 & 0.0001245 & 0.1197033 & 0.1195787 \\
\hline & & PB & -0.0000712 & -0.0000003 & 0.0617289 & 0.0000710 & 0.0618001 & 0.0617291 \\
\hline SZSE & OLS & PE & -0.0001313 & 0.0000000 & 0.0041291 & 0.0001313 & 0.0042604 & 0.0041291 \\
\hline \multirow[t]{5}{*}{ Component } & & $\mathrm{PB}$ & -0.0001655 & -0.0000024 & 0.1142339 & 0.0001631 & 0.1143994 & 0.1142363 \\
\hline & AOLS & $\mathrm{PE}$ & -0.0000679 & -0.0000011 & 0.0871913 & 0.0000667 & 0.0872591 & 0.0871924 \\
\hline & & PB & -0.0000673 & 0.0000002 & -0.0908400 & 0.0000675 & -0.0909073 & -0.0908398 \\
\hline & FGLS & $\mathrm{PE}$ & -0.0000167 & 0.0000014 & -0.0044918 & 0.0000181 & -0.0044751 & -0.0044932 \\
\hline & & $\mathrm{PB}$ & 0.0001951 & -0.0000097 & 0.1877065 & -0.0002049 & 0.1879017 & 0.1876968 \\
\hline
\end{tabular}

1) This table presents the difference between the investors' utility obtained from the utility function including different measures of skewness. 2) Column 2 indicates the estimator being used in the predictive regression model, conventional ordinary least squares estimator (OLS), adjusted ordinary least squares estimator (AOLS) proposed in Lewellen (2004), and flexible generalized least squares (FGLS) estimator suggested in Westerlund and Narayan (2015a). 3) Column 3 indicates the predictor being used in the predictive regression model. 4) Columns 4 to 9 indicate the difference between the utility function including different measures of skewness. $S K_{1}$ is the Fisher-Pearson coefficient of skewness (Equation (6)), $S K_{2}$ is the adjusted Fisher-Pearson standardized moment coefficient (Equation (8)), $S K_{3}$ is the skewness coefficient used in EViews (Equation (9)), and $S K_{4}$ is the skewness coefficient previously used in some older mathematical textbooks. 5) Positive difference implies that if we let skewness come into play in preference, it will be preferred to these utility functions without a skewness measure.

offer the investors higher utility gain from a skewness-based utility function although PB has less predictive utility than another predictor, price-to-earnings ratio (PE).

The main purpose of this study is to compare the skewness calculated differently since there is no single way to measure the skewness. The difference in utility allows us to measure the relevance of skewness for investors. The results of the comparison among different definitions of skewness are presented in $\mathrm{Ta}$ ble 5. The difference in utility between $S K_{1}$ and $S K_{2}\left[U_{3(S K 1)}-U_{3(S K 2)}\right]$ are almost all negative; however, that between $S K_{2}$ and $S K_{3}\left[U_{3(S K 2)}-U_{3(S K 3)}\right], S K_{2}$ 
and $S K_{4}\left[U_{3(S K 2)}-U_{3(S K 4)}\right]$ are almost all positive. These results indicate the skewness coefficient calculated by the definition $S K_{2}$ which is commonly used by common statistical software may provide a higher utility and suggest that $S K_{2}$ is relatively more important in maximizing the investor utility than the other three measure definitions. Regarding the almost forgotten definition of skewness $\left(S K_{4}\right)$, the results indicate $S K_{4}$ provides fewer gain in utility than the other three definitions. The comparisons between $S K_{1}$ and $S K_{3}$ show controversial results.

\section{Conclusions}

Study on stock return predictability and its economic significance are popular in the recent years. The common way to measure the economic significance is to calculate the investor's utility by utility function. The major focus in this study is to argue whether the third moment added to the mean-variance utility function may provide higher utility to the investors. If so, we have to develop a mean-variance-skewness utility function to measure the investor's utility.

Using the time series daily data of four major stock market indices of China stock markets (Shanghai Stock Exchanges and Shenzhen Stock Exchanges), we find evidence that the price-to-earnings ratio $(\mathrm{PE})$ may provide a better predictive ability than the other financial ratio variable price-to-book ratio (PB). Since the time series are diagnosed to be persistent, endogenous, and having heteroskedastic characteristics, flexible generalized least squares estimator (FGLS) are expected to provide unbiased and efficient estimator than the conventional OLS. We find strong evidence to support that FGLS performs better in forecasting. We then test for economic significance by evaluating the investor's utility. We find that economic significance of stock market predictability may benefit from using a utility function that including skewness factor in addition to the expected return forecasts and the variance of the return forecasts. The contribution of our study to the literature is the comparison of different skewness definitions since there is no single way to compute the skewness coefficient. We find the adjusted Fisher-Pearson skewness coefficient which is utilized by most popular statistical software packages may provide the highest investor's utility gain than the other three definitions: one was used in older version of statistical package, one is used by a popular econometric package, and one is almost forgotten.

This study is an empirical study on the comparison of different calculations of skewness factor. Future studies could consider evaluating the economic significance of the stock return predictability by including the fourth moment, kurtosis, in the investor's utility function. There are extensive studies done to find the investment returns are mostly platykurtic or leptokurtic. A leptokurtic return distribution tells the investors that risk is coming mostly from outlier events, something that conservative investors may not be very comfortable with. However, other investors may have an appetite for extreme event risk and are looking for such a distribution. 


\section{References}

[1] Campbell, J.Y. and Shiller, R.J. (1988a) The Dividend-Price Ratio and Expectations of Future Dividends and Discount Factors. Review of Financial Studies, 1, 195-228. https://doi.org/10.1093/rfs/1.3.195

[2] Campbell, J.Y. and Shiller, R.J. (1988b) Stock Prices, Earnings, and Expected Dividends. Journal of Finance, 43, 661-676. https://doi.org/10.1111/j.1540-6261.1988.tb04598.x

[3] Fama, E.F. and French, K.R. (1988) Dividend Yields and Expected Stock Returns. Journal of Financial Economics, 22, 3-25. https://doi.org/10.1016/0304-405X(88)90020-7

[4] Kothari, S.P. and Shanken, J. (1997) Book-To-Market, Dividend Yield, and Expected Market Returns: A Time Series Analysis. Journal of Financial Economics, 44, 169-203. https://doi.org/10.1016/S0304-405X(97)00002-0

[5] Lamont, O. (1998) Earnings and Expected Returns. Journal of Finance, 53, 1563-1587. https://doi.org/10.1111/0022-1082.00065

[6] Lewellen, J. (2004) Predicting Returns with Financial Ratios. Journal of Financial Economics, 74, 209-235.

[7] Campbell, J.Y. and Yogo, M. (2006) Efficient Tests of Stock Return Predictability. Journal of Financial Economics, 81, 27-60.

[8] Chen, S.S. (2009) Predicting the Bear Stock Market: Macroeconomic Variables as Leading Indicators. Journal of Banking and Finance, 33, 211-223.

[9] Westerlund, J. and Narayan, P. (2012) Does the Choice of Estimator Matter When Forecasting Returns? Journal of Banking and Finance, 36, 2632-2640.

[10] Westerlund, J. and Narayan, P. (2015) A Random Coefficient Approach to the Predictability of Stock Returns in Panels. Journal of Financial Econometrics, 13, 605-664. https://doi.org/10.1093/jjfinec/nbu003

[11] Ibbotson, R.G. (1975) Price Performance of Common Stock New Issues. Journal of Financial Economics, 2, 235-272.

[12] Prakash, A.J., de Boyrie, M. and Moncarz, R. (2000) Is CAPM Applicable to the Latin American Capital Markets. Paper Presented at the International Trace and Finance Meetings, Montpellier.

[13] Tobin, J. (1958) Liquidity Preference as Behavior towards Risk. Review of Economic Studies, 25, 65-86. https://doi.org/10.2307/2296205

[14] Pratt, J.W. (1964) Risk Aversion in the Small and in the Large. Econometrica, 32, 122-136. https://doi.org/10.2307/1913738

[15] Arditti, F.D. (1967) Risk and the Required Return on Equity. Journal of Finance, 22, 19-36. https://doi.org/10.1111/j.1540-6261.1967.tb01651.x

[16] Kraus, A. and Litzenberger, R.H. (1976) Skewness Preference and the Valuation of Risk Assets. Journal of Finance, 31, 1085-1100.

[17] Prakash, A.J. and Bear, R.M. (1986) A Simplifying Performance Measure Recognizing Skewness. Financial Review, 21, 135-144. https://doi.org/10.1111/j.1540-6288.1986.tb01112.x

[18] Stephens, A. and Proffitt, D. (1991) Performance Measurement When Return Distributions Are Nonsymmetric. Quarterly Journal of Business and Economics, 30, 23-41.

[19] Lai, T.Y. (1991) Portfolio Selection with Skewness: A Multiple-Objective Approach. Review of Quantitative Finance and Accounting, 1, 293-305. 
https://doi.org/10.1007/BF02408382

[20] Chunhachinda, P., Dandapanib, K., Hamidb, S. and Prakash, A.J. (1997) Portfolio Selection and Skewness: Evidence from International Stock Markets. Journal of Banking \& Finance, 21, 143-167.

[21] Prakash, A.J., Chang, C.H. and Pactwa, T.E. (2003) Selecting a Portfolio with Skewness: Recent Evidence from US, European, and Latin American Equity Markets. Journal of Banking and Finance, 27, 1375-1390.

[22] Bhattacharya, N. (2003) From Mean Variance Space to Mean Skewness Space-Implications for Simultaneous Risk Seeking and Risk Averting Behavior. http://ssrn.com/author $=115728$

[23] Patton, A.J. (2004) On the Out-of-Sample Importance of Skewness and Asymmetric Dependence for Asset Allocation. Journal of Financial Econometrics, 2, 130-168. https://doi.org/10.1093/jifinec/nbh006

[24] Jondeau, E. and Rockinger, M. (2006) Optimal Portfolio Allocation under Higher Moments. European Financial Management, 12, 29-55. https://doi.org/10.1111/j.1354-7798.2006.00309.x

[25] Mitton, T. and Vorkink, K. (2007) Equilibrium under Diversification and the Preference for Skewness. Review of Financial Studies, 20, 1255-1288. https://doi.org/10.1093/revfin/hhm011

[26] Westerlund, J. and Narayan, P. (2015) Testing for Predictability in Conditionally Heteroskedastic Stock Returns. Journal of Financial Econometrics, 13, 342-375. https://doi.org/10.1093/jjfinec/nbu001

[27] Levy, H. and Markowitz, H. (1979) Approximating Expected Utility by a Function of Mean and Variance. American Economic Review, 69, 308-317.

[28] Hlawitschka, W. (1994) The Empirical Nature of Taylor-Series Approximation to Expected Utility. American Economic Review, 84, 713-719.

[29] Scott, R. and Horvath, P. (1980) On the Direction of Preference for Moments of Higher Order than the Variance. Journal of Finance, 35, 915-919. https://doi.org/10.1111/j.1540-6261.1980.tb03509.x

[30] Pearson, K. (1895) Contributions to the Mathematical Theory of Evolution, II: Skew Variation in Homogeneous Material. Transaction of the Royal Philosophical Society, Series $A, 186,343-414$.

[31] Jones, D.N. and Gill, C.A. (1998) Comparing Measures of Sample Skewness and Kurtosis. The Statistician, 47, 183-189. https://doi.org/10.1111/1467-9884.00122

[32] Yule, G.U. and Kendall, M.G. (1950) An Introduction to the Theory of Statistics. 3rd Edition, Harper Publishing Company, 162-163.

[33] Clark, C.T. and Schkade, L.L. (1974) Statistical Analysis for Administrative Decisions. 2nd Edition, South-Western Publishing Co., 42. 